\title{
Improving the efficiency of organic light emitting devices by using co-host electron transport layer
}

\author{
W.C.H. Choy*, K.N. Hui, H.H. Fong, Y.J. Liang, and P.C. Chui \\ Department of Electrical and Electronic Engineering \\ The University of Hong Kong, Pokfulam road, Hong Kong, China
}

\begin{abstract}
By engineering a new cohosting system of tris(8-hydroxyquinoline) and 4,7-diphenyl1,10-phenanthroline in the electron transport layer, the current efficiency of the organic light emitting diode is improved by $34 \%$ to $4.3 \mathrm{~cd} / \mathrm{A}$ as compared to the device with a single host of $\mathrm{Alq}_{3}$ as the electron transport layer. The maximum luminance is over $16000 \mathrm{~cd} / \mathrm{m}^{2}$ at the bias of $22 \mathrm{~V}$ and the current of $475 \mathrm{~mA} / \mathrm{cm}^{2}$, which is $\sim 73 \%$ higher than the single host $\mathrm{Alq}_{3}$ device without optimizing the layer thickness. The reasons for the improvement will be investigated. The results strongly indicate that the knowledge of bulk conductivity engineering of organic n-type transporters shows practical significance in OLED applications.
\end{abstract}

PACS: $61.43-\mathrm{j}, 72.20-\mathrm{i}, 72.80 \mathrm{Tm}, 73.61 . \mathrm{Ph}$

Keywords: Tris (8-hydroxyquinoline) aluminum, 1,10-phenanthroline, mobility, electron transport, co-host

* Author to whom correspondence and requests for materials should be addressed. Email: chchoy@eee.hku.hk 


\section{Introduction}

Tris (8-hydroxyquinoline) aluminum $\left(\mathrm{Alq}_{3}\right)$ has been commonly used as an organic light-emitting host as well as electron transport layer (ETL) in organic lightemitting diodes (OLEDs). However, due to its lower electron mobility of $10^{-6} \mathrm{~cm}^{2} \mathrm{~V}^{-1} \mathrm{~s}^{-1}$ [1-3], $\mathrm{Alq}_{3}$ is one of the key sources responsible for the undesirable predominant voltage drop in $\mathrm{Alq}_{3}$-based devices [4]. Furthermore, the operation lifetime of $\mathrm{Alq}_{3}$ based devices is reduced due to the unbalanced charge accumulation originated from an excessive hole injection into the $\mathrm{Alq}_{3}$ layer [5]. Extra amount of holes also generate non-emissive cationic species in the $\mathrm{Alq}_{3}$ and result in the formation of dark spots [6]. Hence, enhancement of electron conduction in the ETL of OLEDs is a critical approach to both lowering the driving voltage and improving the operation lifetime. Recently, although some electron transporting materials such as phenanthroline and oxadiazole compounds were suggested for replacing the $\mathrm{Alq}_{3}$ as the ETL due to their improved drift electron mobility [7-10], the device reliability including film stability and thermal endurance have not yet fulfilled the requirement of commercial display application [10-11]. The highly reactive metal (e.g. Li) doping reported by Kido et al [12] is an alternative means to enhance the device electron conduction, although photoluminescence quenching occurs if the doped region exceeds $30 \mathrm{~nm}$.

In our study, we establish an organic based co-host composite to replace the traditional single host ETL. The results conclude that our approach improves the electron conductivity on the ETL without affecting the film stability, resulting in an improved current efficiency of about $34 \%$ through employing a ET composite of phenanthroline : 
hydroxyquinoline. It is important to note that 4,7-diphenyl-1,10-phenanthroline (BPhen) is chosen for mixing with $\mathrm{Alq}_{3}$ to form the co-host ETL since it possesses a considerable high electron mobility $\left(\sim 5 \times 10^{-4} \mathrm{~cm}^{2} \mathrm{~V}^{-1} \mathrm{~s}^{-1}\right)$ among the electron-dominant materials [10]. This report focuses mainly on the device aspect by applying the knowledge of bulk conduction presented previously. The composition of the BPhen:Alq $\mathrm{A}_{3}$ co-host electron transporter based devices will be investigated.

\section{Experimental}

The indium-tin-oxide (ITO) substrates with a size of $25 \times 25 \mathrm{~mm}^{2}$ and resistivity of $80 \mathrm{ohm} / \mathrm{square}$ were cleaned prior to loading into the evaporation chamber through scrubbing by detergent and soaking into de-ionized (DI) water for 10min in each step. The evaporation chamber is operated at $\sim 10^{-7}$ Torr. The substrates were then immersed into ultrasonic bath of DI water, ethanol and acetone for $20 \mathrm{~min}$ for each solvent. The solvent cleaned ITOs were further treated in UV ozone for $20 \mathrm{~min}$.

The organic materials used in this study were shown in Fig. 1. They were $\mathrm{Alq}_{3}$ acted as ETL and light emitting layer (EML), $N, N^{\prime}$-bis(1-naphthyl)- $N, N^{\prime}$-diphenyl-1,1'-biphenyl4,4'-diamine (NPD) as a host transport layer (HTL), BPhen as ETL, and copper phthalocyanine (CuPc) for stabilizing the ITO surface and LiF as the electron injection layer (EIL). The materials were purified by gradient sublimation prior to thin-film coating when BPhen was used without further purification. The deposition rate for CuPc, $\mathrm{Alq}_{3}$, NPD, BPhen was typically 1.0-2.0 $\AA /$ s. The deposition rates of LiF and Al were 0.1 $\AA / \mathrm{s}$ and $10-15 \AA / \mathrm{s}$, respectively. Film thickness was monitored in situ using the quartz 
crystal monitor and ex situ by a stylus profilometer (Tencor $\alpha$-step 500). The emission area of devices is $4.57 \mathrm{~mm}^{2}$.

To investigate the contributions of the co-host electron transport composite, three devices containing different ETLs have been prepared: (i) device $\mathbf{A}$ - Alq A $_{3}$ (ii) device $\mathbf{B}$ - BPhen; and (iii) device $\mathbf{C}-n$ wt\% BPhen-doped $\mathrm{Alq}_{3}$. The undoped EML device has a structure:

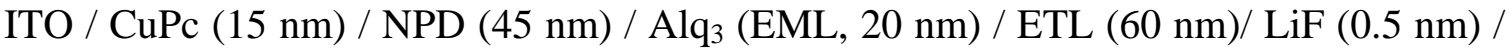
$\mathrm{Al}$ as shown in Fig. 1(b). The devices were characterized in room ambient without encapsulation. The current density-voltage-luminance (J-V-L) characteristics of the devices were measured with International Light IL1400A Photometer and a programmable Keithley source meter 2400.

\section{Results and discussion}

Fig. 2 shows the luminous efficiency of undoped devices with various compositions of ET hosts incorporating BPhen and $\mathrm{Alq}_{3}$. In the typical device using $\mathrm{Alq}_{3}$ as the ETL (device A), the efficiency is $\sim 3 \mathrm{~cd} / \mathrm{A}$ at $20 \mathrm{~mA} / \mathrm{cm}^{2}$, similar to the reported values [13]. Replacing ETL by BPhen (device B), the efficiency is significantly enhanced by $\sim 34 \%$, to $4.3 \mathrm{~cd} / \mathrm{A}$. The time-of-flight results indicate that under an applied electric field of $\sim 1 \mathrm{MV} / \mathrm{cm}$, the electron mobility of $\mathrm{Alq}_{3}$ has a value of $\sim 10^{-6} \mathrm{~cm}^{2} \mathrm{~V}^{-1} \mathrm{~s}^{-1}$ [1-3] while that of BPhen exhibits a much higher electron mobility of $5 \times 10^{-4} \mathrm{~cm}^{2} \mathrm{~V}^{-1} \mathrm{~s}^{-1}$ [10]. With higher electron drift mobility, BPhen-type ETL possesses better electron conduction and thus a higher charge recombination in the Alqu based light-emitting devices. As a result, electron drift mobility difference between BPhen and $\mathrm{Alq}_{3}$ can be 
seen as responsible for the dramatic change in the device's luminous efficiency. In addition, when the BPhen concentration is increased in the BPhen:Alq ${ }_{3}$ co-host, the efficiency increases. It suggests that more electrons are transferred into the EML which will be discussed in detail later. Consequently, BPhen:Alq ${ }_{3}$ forms a promising electron transporting layer in $\mathrm{Alq}_{3}$-based OLEDs.

It is worth to note that while the device can still benefit from the co-host approach to maximize the efficiency at the BPhen composition of $>50 \mathrm{wt} \%$. It would encounter the problem of re-crystallization with its ETL containing a pristine or heavily-doped Bphen [14]. Therefore, in the following discussion, we will focus on improvement of the device performance by employing $50 \mathrm{wt} \%$ BPhen:Alq ${ }_{3}$ co-host structure.

Two testing devices with difference in ETL only: device $\mathbf{A}$ - a single $\mathrm{Alq}_{3}$ host and device C - a 50 wt\% BPhen:Alq ${ }_{3}$ co-host have been investigated. Their device performances are shown in Fig. 3. As illustrated in the current-voltage (I-V) curves of Fig. 3(a), the driving voltage required for the device to operate at a current of $20 \mathrm{~mA} / \mathrm{cm}^{2}$ is reduced from 14.3 to $10.8 \mathrm{~V}$ by introducing a BPhen:Alq $\mathrm{A}_{3}$ co-host ETL. Meanwhile, the corresponding luminance increases from $580 \mathrm{~cd} / \mathrm{m}^{2}$ to $760 \mathrm{~cd} / \mathrm{m}^{2}$, as shown in Fig. 3(b). Without thickness optimization, the maximum luminance of the co-host device is over $16,000 \mathrm{~cd} / \mathrm{m}^{2}$ at a current of $475 \mathrm{~mA} / \mathrm{cm}^{2}$ and bias of $22 \mathrm{~V}$; this is $\sim 73 \%$ higher than the single $\mathrm{Alq}_{3}$ host device. 
Besides the merit of the high drift mobility of BPhen, the noticeable achievement of the BPhen:Alq ${ }_{3}$ co-host is also contributed by the similar electron hopping along their lowest unoccupied molecular orbitals (LUMOs). The LUMO of $\mathrm{Alq}_{3}$ and BPhen are similar with a value of $3 \mathrm{eV}$ [15]. Therefore, it is believed that electrons hop freely at both $\mathrm{Alq}_{3}$ and BPhen in the co-host device as shown in Fig. 4 while in a single host device, electrons hop merely along the LUMO in $\mathrm{Alq}_{3}$. Moreover, no shifting to higher operating voltage in the I-V characteristics has been observed in the devices with different compositions of BPhen:Alq ${ }_{3}$. This also implies that electron trapping due to the introduction of BPhen does not occur when the BPhen concentration is beyond $10 \mathrm{wt} \%$.

In addition, the transport of electrons can be adjusted by varying the weight ratio of BPhen:Alq ${ }_{3}$ in the mixed co-host ETL layer. By increasing the BPhen:Alq ${ }_{3}$ weight ratio, the probability of hopping via the LUMO of BPhen will be increased, resulting in the increase of electron mobility in co-host ETL. Our results show that the current efficiency improves through increasing the weight ratio of BPhen, although the high concentration of Bphen causes the trend of crystallization of BPhen [14] when the weight ratio increases beyond the $50 \% \mathrm{BPhen}: 50 \% \mathrm{Alq}_{3}$. Furthermore, the largely negative highest occupied molecular orbital (HOMO) bands of BPhen with a value of $\sim 6.4 \mathrm{eV}$ in the cohost ETL matrix effectively blocks the holes from penetrating through BPhen:Alq ${ }_{3}$ cohost ETL, and confines excitons in EML. Consequently, the performance of the devices with co-host ETL can also be improved as compared to that of conventional single $\mathrm{Alq}_{3}$ devices through better balance of the number of holes and electrons and confining the excitons within the EML. 


\section{Conclusion}

A new method of co-hosting hydroxyquinoline with phenanthroline derivative for improving the electron mobility of ETL has been introduced in this paper. Thanks to (a) the superior electron mobility of BPhen, (b) free electron hopping in ETL due to similar LUMO value of both $\mathrm{Alq}_{3}$ and BPhen, and (c) high HUMO value of BPhen for reducing the hole injection into the ETL, the current efficiency of the cohost device is increased by $34 \%$ to $4.3 \mathrm{~cd} / \mathrm{A}$ as compared to the conventional structure with single host of $\mathrm{Alq}_{3}$ when the weight ratio of BPhen:Alq ${ }_{3}$ is 50:50. The further increment of BPhen content will cause the trend of crystallization of BPhen at high concentration. Without any optimization of the layer thickness, the maximum luminance of the co-host device is over $16,000 \mathrm{~cd} / \mathrm{m}^{2}$ at a current of $475 \mathrm{~mA} / \mathrm{cm}^{2}$ and bias of $22 \mathrm{~V}$, which is $\sim 73 \%$ higher than the single $\mathrm{Alq}_{3}$ host devices.

\section{Acknowledgement}

The authors would like to acknowledge the support of the grant from the Research Grant Council of the Hong Kong Special Administrative Region, China, UDF grant and seed funding of The University of Hong Kong. P.C Chui would also like to acknowledge the support of the university’s Small Project Funding. 


\section{Reference}

[1] R. G. Kepler, P. M. Beeson, S. J. Jacobs, R. A. Anderson, M. B. Sinclair, V. S. Valencia and P. A. Cahill: Appl. Phys. Lett., 66 (1995) 3618.

[2] G. G. Malliaras, Y. Shen, D. H. Dunlap, H. Murata and Z. H. Kafafi, Appl. Phys. Lett., 79 (2001) 2582.

[3] H.H. Fong, K.C. Lun, and S.K. So, Jpn. J. of Appl. Phys., 41 (2002) L1122.

[4] M. Hiramoto, K. Koyama, K. Nakayama and M. Yokoyama, Appl. Phys. Lett., 76 (2000) 1336.

[5] H. Aziz, Z.D. Ppovic, N.X. Hu, A.M. Hor, G.Xu, Science, 283 (1999) 1900.

[6] J. McElvain, H. Antoniadis, M. R. Hueschen, J. N. Miller, D. M. Roitman, J. R. Sheats, and R. L. Moon, J. Appl Phys., 80 (1996) 6002.

[7] C. Adachi, T. Tsutsui, T. Saito, Appl. Phys. Lett., 56 (1990) 799.

[8] C. Adachi, T. Tsutsui, T. Saito, Appl. Phys. Lett., 57 (1990) 531.

[9] H. Tokuhisa, M. Era, T. Tsutsui, S. Saito, Appl. Phys. Lett., 66 (1995) 3433.

[10] S. Naka, H. Okada, H. Onnagawa, T. Tsutsui, Appl. Phys. Lett., 76 (2000) 197.

[11] H. Tokuhisa, Masanao Era, T. Tsutsui, S. Saito, Appl. Phys. Lett., 66 (1995) 3433.

[12] J. Kido, T. Matsumoto, Appl. Phys. Lett., 73 (1998) 2866.

[13] C.H. Chen, C. W. Tang, Appl. Phys. Lett., 79 (2001) 3711.

[14] K. Naito, A. Miura, J. Phys. Chem., 97 (1993) 6240.

[15] G. He, M. Pfeiifer, K. Leo, M. Hofmann, J. Birnstock, R. Pudzich, J. Salbeck, Appl. Phys. Lett., 85 (2004) 3911. 


\section{Figure captions}

Fig. 1 (a) Molecular structures of $\mathrm{Alq}_{3}$, BPhen, and NPD. (b) Device configuration: ITO $/ \mathrm{CuPc}(15 \mathrm{~nm}) / \mathrm{NPD}(45 \mathrm{~nm}) / \mathrm{Alq}_{3}(20 \mathrm{~nm}) / \mathrm{ETL}(60 \mathrm{~nm}) / \mathrm{LiF}(0.5 \mathrm{~nm}) / \mathrm{Al}$ (150nm).

Fig. 2 Comparison of luminous efficiency of undoped devices driven at $20 \mathrm{~mA} / \mathrm{cm}^{2}$. The ETL consists of a composite layer of BPhen and $\mathrm{Alq}_{3}$. The total thickness of $\mathrm{Alq}_{3}$ is $700 \mathrm{~nm}$.

Fig. 3 Plots of (a) Current-voltage and (b) Luminance-current of devices without doping the EML: Device A (close circle) contains a single ETL. Device B (close triangle) contains a co-host ETL (50 wt\% BPhen mixed $\mathrm{Alq}_{3}$ ).

Fig. 4 Energy diagram of (a) undoped and (b) 50 wt\% Bphen:Alq ${ }_{3}$ cohost devices. Shaded area indicates the $\mathrm{Alq}_{3}$ based EML. 
Improving the efficiency of ...
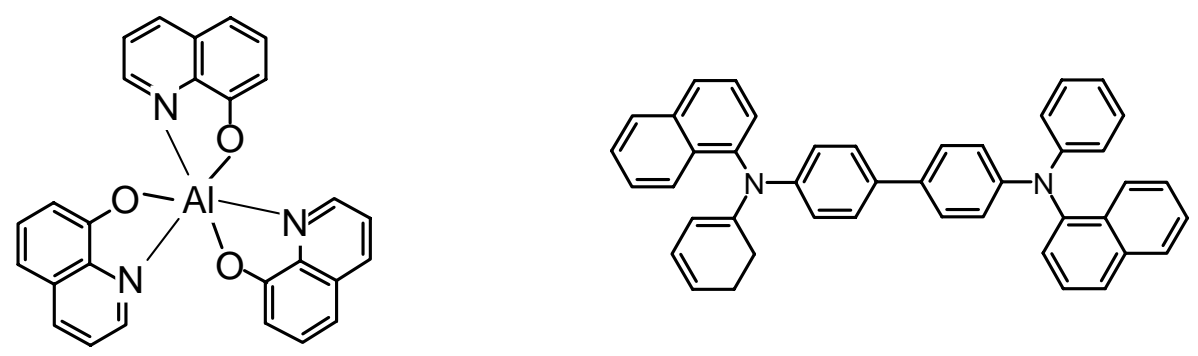

$\mathrm{Alq}_{3}$

NPD<smiles>C1=CC(c2ccccc2)C2C=Cc3c(-c4ccccc4)ccnc3C2=N1</smiles>

BPhen

(a)

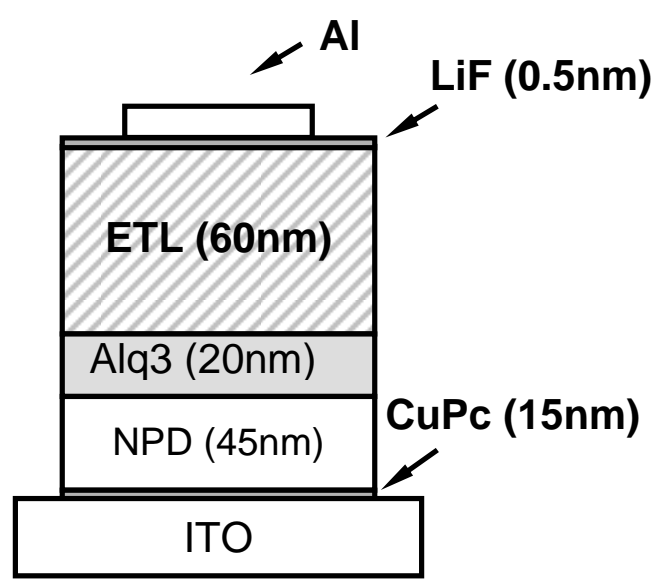

ETL: BPhen, BPhen:Alq ${ }_{3}$, and Alq ${ }_{3}$

(b)

Fig. 1 
Improving the efficiency of ...

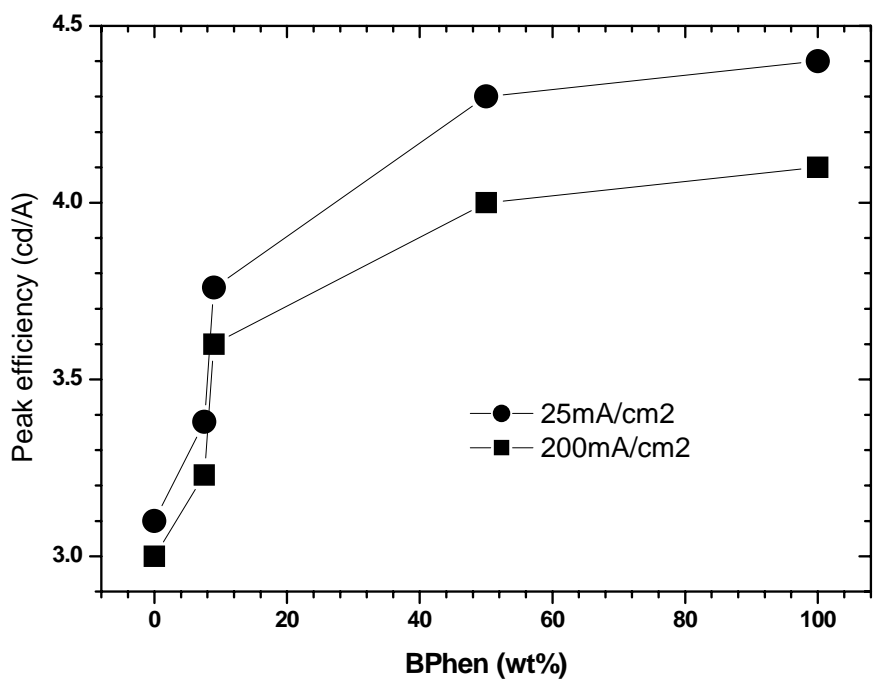

Fig. 2 
Improving the efficiency of ...
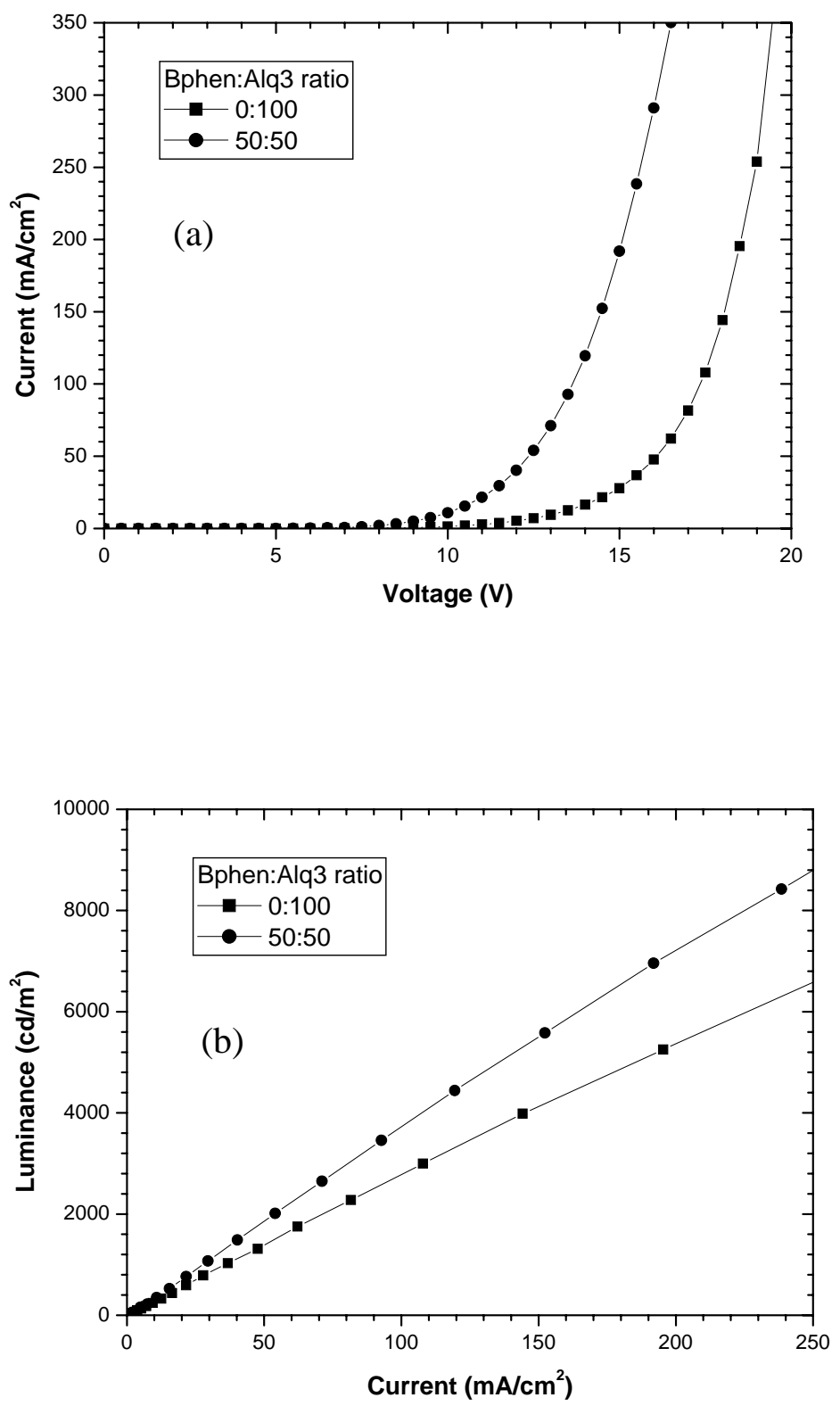

Fig. 3 
Improving the efficiency of ...

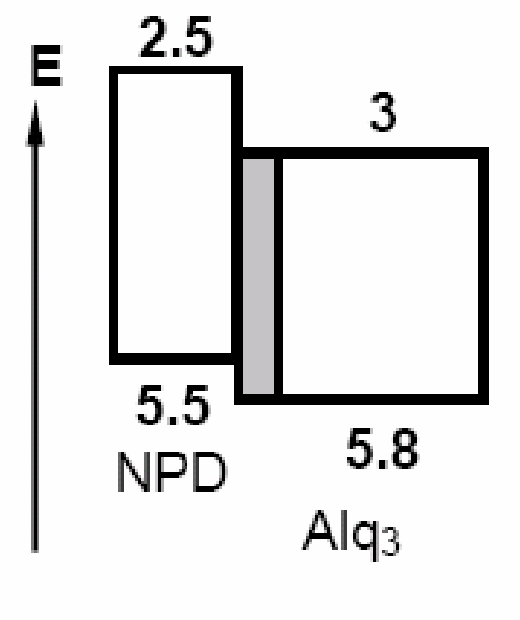

(a)

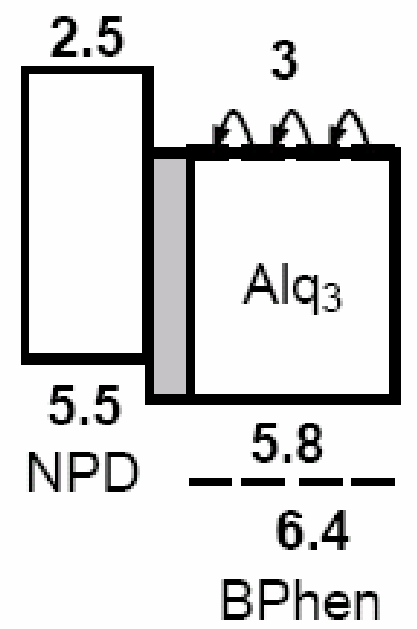

(b)

Fig. 4 